\title{
Understanding of molecular mechanisms in natural killer cell therapy
}

\begin{abstract}
Suk Ran Yoon ${ }^{1,2,3}$, Tae-Don $\mathrm{Kim}^{1,2,3}$ and Inpyo Choi ${ }^{1,2}$
Cancer cells and the immune system are closely related and thus influence each other. Although immune cells can suppress cancer cell growth, cancer cells can evade immune cell attack via immune escape mechanisms. Natural killer (NK) cells kill cancer cells by secreting perforins and granzymes. Upon contact with cancer cells, NK cells form immune synapses to deliver the lethal hit. Mature NK cells are differentiated from hematopoietic stem cells in the bone marrow. They move to lymph nodes, where they are activated through interactions with dendritic cells. Interleukin-15 (IL-15) is a key molecule that activates mature NK cells. The adoptive transfer of NK cells to treat incurable cancer is an attractive approach. A certain number of activated NK cells are required for adoptive NK cell therapy. To prepare these NK cells, mature NK cells can be amplified to obtain sufficient numbers of NK cells. Alternatively, NK cells can be differentiated and amplified from hematopoietic stem cells. In addition, the selection of donors is important to achieve maximal efficacy. In this review, we discuss the overall procedures and strategies of NK cell therapy against cancer.
\end{abstract}

Experimental \& Molecular Medicine (2015) 47, e141; doi:10.1038/emm.2014.114; published online 13 February 2015

\section{INTRODUCTION}

As we gain a better understanding of the molecular mechanisms controlling natural killer (NK) cell activity, the potential of their possible application in cancer immunotherapy grows increasingly. NK cells play key roles in innate and adaptive immune responses through unique NK cell activation mechanisms during early host defense against viruses and tumors by performing two major roles: contact-dependent cytotoxicity and cytokine production for immune modulation. Target cell apoptosis is primarily mediated by perforin (Prf1)- and granzyme B (GzmB)-mediated pathways and the regulation of immune responses is mediated by the secretion of cytokines such as interferon- $\gamma$ and tumor-necrosis factor- $\alpha{ }^{1-3}$

Compared with $\mathrm{T}$ and $\mathrm{B}$ cells, our understanding of the checkpoints and the developmental stages that lead to the generation of cells committed to the NK cell lineage remain poorly defined. The developmental processes that drive hematopoietic stem cells (HSCs) into NK cells are being identified. ${ }^{4}$ Emerging experimental evidence suggests that NK cell differentiation depends on defined cytokines, the temporal induction of several transcription factors and microRNA (miRNA)-based gene expression. ${ }^{5}$ Recently, several research groups have developed protocols for in vitro NK cell differentiation based on reconstitution with cytokines, providing a good strategy for amplifying NK cells for therapeutic applications. ${ }^{6-8}$ Recent advances in understanding the manipulation of NK cell activation and development have led to the hope that NK cells could be harnessed as an immunotherapy for cancers and other diseases.

This review provides the framework for understanding the impact of NK cell activation, development/differentiation and its clinical implications. We summarize sequential activation processes such as priming, immune synapse formation, receptor signaling, effector functions and its manipulation for tuning NK cell activity. In addition, fundamental questions are discussed concerning the development of successful NK cellbased therapies.

\section{NK CELL ACTIVATION}

Current insights into the molecular specificities that regulate NK cell functions in vivo suggest that it might be possible to design NK cell-based immunotherapeutic strategies against human cancer. In this section, we review the overall processes of the NK cell activation mechanisms, including receptor

\footnotetext{
${ }^{1}$ Immunotherapy Research Center, Korea Research Institute of Bioscience and Biotechnology, Daejeon, Republic of Korea and ${ }^{2}$ Department of Functional Genomics, Korea University of Science and Technology, Daejeon, Republic of Korea

${ }^{3}$ These authors contributed equally to this work.

Correspondence: Dr I Choi, Immunotherapy Research Center, Korea Research Institute of Bioscience and Biotechnology, Yuseong-gu, Daejeon 305-806, Republic of Korea.

E-mail: ipchoi@kribb.re.kr

Received 20 October 2014; revised 17 November 2014; accepted 2 December 2014
} 
signaling, immune synapse formation and NK roles, and discuss possible strategies for the NK cell targeting of human tumors and the development of successful NK cell-based therapies. ${ }^{9}$

\section{Receptor signaling}

NK cell activation is controlled by a dynamic balance between the positive and negative signals provided by two main types of receptors. ${ }^{1,2,10,11}$ The receptors-NKG2D, NKp46, NKp30, NKp44, the activating form of killer cell immunoglobulin-like receptor (KIR) known as KIR-S and CD16-provide positive signals, finally triggering cytotoxicity and the production of cytokines. Some of these activating cell surface receptors stimulate protein tyrosine kinase-dependent pathways through reversible associations with transmembrane signaling adaptors. These adaptor proteins harbor cytoplasmic immunoreceptor tyrosine-based activation motifs that consist of a consensus amino-acid sequence with paired tyrosines and leucines $(\mathrm{Yxx}(\mathrm{I} /$ L) $x 6-12 \operatorname{Yxx}(\mathrm{I} / \mathrm{L})){ }^{12}$ These motifs are normally located in the cytoplasmic domains of ligand-binding transmembrane receptors, such as the $\mathrm{T}$ cell receptor and high-affinity immunoglobulin $\mathrm{E}$ receptor (FceRI), and mediate interactions between the transmembrane receptor complex and protein tyrosine kinases that are required to initiate early and late signaling events. Additional cell surface receptors that are not directly coupled to immunoreceptor tyrosine-based activation motifs also participate in NK cell activation. These include NKG2D, which is well associated with the DAP10 transmembrane signaling adaptor, as well as integrins and cytokine receptors. ${ }^{9}$ The discovery of NKG2D ligands, such as MICA, the RAET1 family and the NKp30 ligand B7H6 suggests that such receptors recognize molecules that are rarely present on normal cells but are upregulated during infection or carcinogenesis (Figure 1).

NK cells also express cell surface inhibitory receptors that antagonize activating pathways through protein tyrosine phosphatases. ${ }^{4,12}$ The typical inhibitory receptor KIR recognizes 'self and subsequently provides negative signals finally to suppress NK cell activation by inhibition of stimulatory signaling pathway. The ligand of KIR is major histocompatibility complex (MHC) class I molecules of the self that is present on normal cells. ${ }^{3}$ These inhibitory cell surface receptors are characterized by intracytoplasmic immunoreceptor tyrosine-based inhibition motifs ${ }^{2}$ present in the cytoplasmic domains of several inhibitory receptors. After ligand binding, intracytoplasmic immunoreceptor tyrosine-based inhibition motifs are phosphorylated on their tyrosine residues and recruit lipid or tyrosine phosphatases. The tyrosine phosphorylation status of several signaling components that are substrates for both protein tyrosine kinase and protein tyrosine phosphatases is thus key molecules to the propagation of the NK cell effector pathways. Understanding the integration of these multiple signals is central to the understanding and manipulation of NK cell effector signaling pathways (Figure 1).

Cytokines are important signals for regulating the proliferation, survival, activation status and effector functions of the immune system. In addition, NK cell development, survival

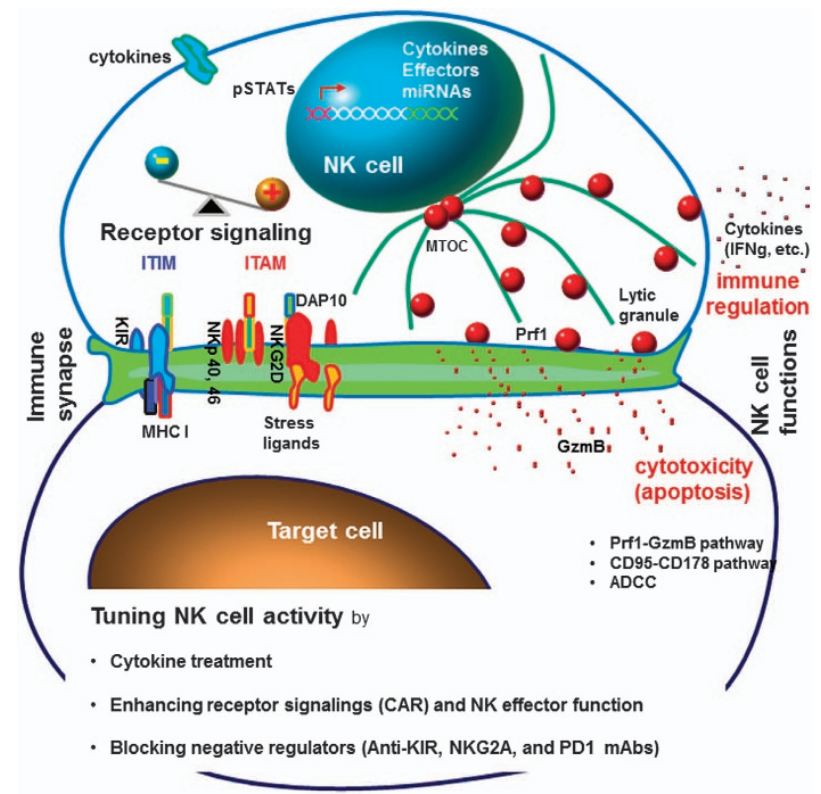

Figure 1 Natural killer (NK) cell activation and its translation to therapeutic application. The encounter between the NK cell and target cell results in adhesion and conjugation (Immune Synapse). The dynamic balance between inhibitory and activating receptor signaling at the cell-cell interface decides the outcome of the immune synapse. Engagement of NK cell activating receptors induces the phosphorylation of ITAM or kinase and tight actin cytoskeleton rearrangements that, in turn, lead to a more stable conjugation (Activation). NK cells can be primed or activated by cytokines locally secreted by other immune cells, inducing various types of immune-related gene expression including cytokines, NK cell effectors and noncoding microRNAs (miRNAs). Sustained stimulatory signaling causes robust actin polymerization and polarization of the MTOC to the immune synapse. Lytic granules containing effectors (for example, GzmB and Prf1) are transported along microtubule tracks for subsequent release. Prf1 and GzmB can induce target cell apoptosis. Upon activation, cytokines, including pro-inflammatory cytokines (for example, interferon- $\gamma$ (IFN- $\gamma$ )), are also secreted for immune regulation (NK cell functions). Major strategies to harness NK cell functions in cancer (Tuning NK cell activity). First, treatment with cytokines promotes NK cell proliferation, differentiation and activation and/or inhibits NK cell suppressors. Second, manipulating the balance between stimulatory and inhibitory signaling can promote NK cell activation through the use of CAR and/or adoptive transfer of allosteric NK cells. In addition, these strategies are focused on NK effector activation by promoting TRAIL (tumor-necrosis factor (TNF)related apoptosis-inducing ligand) or CD178 expression, as well as ADCC activation via engineered Fc. Third, these strategies may be enhanced by anti-inhibitory antibodies specific for negative regulators such as KIR, NKG2A and PD1. ADCC, antibody-dependent cellular cytotoxicity; CAR, chimeric antigen receptor; GzmB, granzyme B; ITAM, immunoreceptor tyrosine-based activation motif; ITIM, immunoreceptor tyrosine-based inhibitory motif; KIR, killer cell immunoglobulin-like receptor; MHC, major histocompatibility; MTOC, microtubule-organizing center; PD1, programmed cell death 1; Prf1, perforin; -, NK cell inhibition; +, NK cell activation. Substances that act on NK cells are indicated in red text.

and function require cytokines, including interleukin (IL)-2, IL-12, IL-15, IL-18 and IL-21. ${ }^{13}$ Among these, IL-15 has been shown to play a key role in NK cell development and priming 
for activation, based on studies on IL-15 or IL-15 receptordeficient mice. ${ }^{14,15}$ In a recent report on the development of innate NK cell memory, a brief, combined activation with IL-12, IL-15 and IL-18 resulted in the generation of long-lived NK cells that exhibited enhanced functionality when they encountered a secondary stimulation, ${ }^{16}$ providing a new possibility of enhancing NK cell responsiveness to viral infections and tumors. An improved understanding of the cellular and molecular networks of cytokine-cytokine receptor signals has led to a resurgence of interest in the clinical use of cytokines that can sustain and/or activate NK cell antitumor potential.

\section{Immune synapse formation}

As with other immune cells, the majority of NK cell effector functions require direct cell-to-cell contact. Target cell binding is accompanied by the creation of complex structures at the cell-cell interface, often considered the immune synapse. ${ }^{12,17}$ This concept was first proposed by DM Davis in 1999 as the 'missing-self recognition in inhibitory interactions. ${ }^{18}$ Recent progress has contributed to the characterization of several types of NK cell immunological synapses and has demonstrated that NK cell immune synapses are the primary sites where the highly complex regulation of NK cell activity occurs. ${ }^{9,19}$ The NK cell immunological synapse is the dynamic interface formed between an NK cell and its target cell. The formation of the NK cell immunological synapse involves several distinct stages, from the initiation of contact with a target cell to the directed delivery of lytic granule contents for target cell lysis. ${ }^{17}$ Progression through the individual stages is regulated, and this tight regulation underlies the precision with which NK cells select and kill susceptible target cells, including virally infected transformed cells and tumor cells that they encounter during their surveillance of the body.

\section{Effector molecules}

Several killing pathways in NK cell cytotoxicity have been characterized. ${ }^{1,4}$ First, the Prf1- and GzmB-mediated mechanism demonstrates that granzymes are serine proteases that are found primarily in the cytoplasmic granules of NK cells. Prf1 facilitates the delivery of Gzms into the cytosol of the target cell, whereas GzmB, the best-characterized Gzm, cleaves several procaspases and other intracellular substrates to initiate the classical apoptotic pathways. Second, the CD95 (FAS)-CD178 (FAS ligand) pathway leads to the formation of a deathinducing signaling complex and the subsequent activation of caspases that promote the apoptotic process of the CD95expressing target cell. Third, the antibody-dependent cellular cytotoxicity mechanism is used by leukocytes, including NK cells that express CD16 (Fc receptors) to kill antibody-coated target cells (Figure 1).

Among these cytotoxic effector molecules, the most general and best-known effectors are Prf1 and GzmB. ${ }^{20}$ The contact between an NK cell and a susceptible target cell results in conjugation and the formation of the immunological synapse. The stimulation of NK cell-activating receptors by their ligands on the target cell induces the phosphorylation of membrane proximal signaling molecules and the formation of a signaling complex comprising many signaling and adapter molecules at the junction. Positive feedback loops are generated, causing signal amplification and sustained signaling that induce more robust actin polymerization at the synapse zone and polarization of the microtubule-organizing center and lytic granules to the immunological synapse, where Prf1 and GzmB from lytic granules are subsequently exocytosed to the target cell membrane. ${ }^{12}$

\section{MicroRNAs in NK cell biology}

The miRNAs are an abundant class of endogenous small noncoding RNAs (19-22 nucleotides) generated by the sequential processing of primary miRNA transcripts by the ribonucleases Drosha in the nucleus and Dicerl in the cytoplasm. Mature miRNAs associate with the 3' untranslated regions of specific target mRNAs to downregulate gene expression by targeting mRNAs for translational suppression or mRNA degradation. Recently, the involvement of miRNAs in immune responses and the development of NK cells from hematopoietic stem cells has been widely investigated by gain and loss of function of specific miRNAs or by disruption of the molecules involved in the biogenesis/activity of all miRNAs (for example, Argonaute, Drosha and Dicer). ${ }^{21}$ The miRNAs also regulate fundamental NK cell processes such as development, proliferation, cytotoxicity and cytokine production, as shown in Table 1. The growing evidence for the impact of miRNAs on NK cell biology suggests that modulating the endogenous levels of a specific miRNA in NK cells represents a potential strategy for immunotherapy. ${ }^{5,22}$

\section{Tuning of NK cell activation}

Upon tuning the threshold for NK cell activation, NK cells can exert effector functions against transformed self while

Table 1 Selected microRNA with roles in NK cell biology

\begin{tabular}{|c|c|c|}
\hline MicroRNA & Target genes & $\begin{array}{l}\text { Cell type miRNA } \\
\text { expression }\end{array}$ \\
\hline miR-27a* & Human Prf1 and GzmB 6 & Mature NK cells \\
\hline \multirow[t]{3}{*}{ miR-150 } & Mouse c-Myb123 & Developing NK cells \\
\hline & Prf1, human and mouse $\mathrm{e}^{124}$ & Mature NK cells \\
\hline & Human and mouse IFN $\gamma^{123}$ & Mature NK cells \\
\hline miR-223 & Mouse GzmB ${ }^{125}$ & Mature NK cells \\
\hline miR-378, 30e & Human Prf1 and GzmB 126 & Mature NK cells \\
\hline \multirow[t]{3}{*}{ miR-155 } & Human and mouse IFN $\gamma^{127}$ & Mature NK cells \\
\hline & SHIP-1, human 21 & Mature NK cells \\
\hline & Noxa and SOCS1, mouse ${ }^{128}$ & Mature NK cells \\
\hline miR-181 & Human and mouse IFN $\gamma^{129}$ & Mature NK cells \\
\hline miR-29 & Human and mouse IFN $\gamma^{130}$ & Mature NK cells \\
\hline miR-132, 212, 200a, & STAT4, human 131 & Mature NK cells \\
\hline miR-183 & DAP12, human 132 & Mature NK cells \\
\hline
\end{tabular}

Abbreviations: DAP12, DNAX activation protein of $12 \mathrm{kDa}$; GzmB, granzyme B; IFN $\gamma$, interferon- $\gamma$; miRNA, microRNA; NK, natural killer; Prf1, perforin; SHIP-1, $\mathrm{SH} 2$ (Src homology 2)-containing inositol phosphatase-1; SOCS1, suppressor of cytokine signaling 1 ; STAT4, signal transducer and activator of transcription 4. 
sustaining tolerance to normal self. Recent progress in understanding NK cell biology brings this approach into the realm of clinical trials. An emerging idea is that the threshold of NK cell reactivity is tuned by their interactions with the environment. As shown in the lower panel of Figure 1, the strategies used to harness NK cell functions in cancer therapy can be summarized into three categories: ${ }^{23}$ (1) enhancing receptor signaling by manipulating the balance between inhibitory and activating NK receptors and NK cell effector functions, (2) blocking negative regulators through the use of monoclonal antibodies and (3) treatment involving cytokines that promote NK cell proliferation, viability and activity.

\section{NK CELL GENERATION}

\section{NK cell development}

NK cells have been known to originate from hematopoietic precursor cells in the bone marrow (BM) ${ }^{24}$ However, hematopoietic precursor cells are also found in the lymph nodes and secondary lymphoid tissues, ${ }^{8}$ the maternal decida ${ }^{25}$ and the thymus and liver of the fetus. ${ }^{26,27}$ Nevertheless, NK cell development primarily occurs in the BM microenvironment.

In general, NK cells are derived from $\mathrm{CD} 34^{+}$HSCs through discrete stages of development, such as precursor NK (pNK), immature NK (iNK) and mature NK, and are characterized by the sequential acquisition of surface receptors and effector function. ${ }^{28,29}$ HSCs give rise to different hematopoietic lineages via common lymphoid progenitors and common myeloid progenitors. Common lymphoid progenitors differentiate into NK/T progenitors that have the potential to develop into $\mathrm{T}$ and/or NK cells. Following this, NK/T cells differentiate into pNK and iNK and finally into mature NK. ${ }^{8,30}$ Recently, Grzywacz et al. ${ }^{31}$ demonstrated that NK cells could also be derived from myeloid precursors such as common myeloid progenitors and the $\mathrm{CD} 33^{+} \mathrm{CD} 13^{+}$population. The transition from NK/T to pNK cells is defined by the expression of IL-2/15R $\beta$ (the CD122 receptor). ${ }^{26}$ Along with IL-2R $\beta$ expression, IL-7, stem cell factor and Flt3L (FMS-like tyrosine kinase 3 ligand) commit HSCs to the NK lineage. ${ }^{32}$ In humans, pNKs are characterized by the $\mathrm{CD} 34^{+} \mathrm{CD} 122^{+} \mathrm{CD} 56^{-}$phenotype, and these pNK cells then respond to IL-15, a critical factor for the final maturation of NK cells.

As the cells differentiate from pNK to iNK cells, the expression of Flt3 and IL-7R $\alpha$ decreases, whereas the expression of IL-2R $\beta$, CD2 and 2B4 (CD244) increases. ${ }^{33,34}$ The iNK cells are identified by the expression of CD161 that is supported by a population of $\mathrm{CD} 3^{-} \mathrm{CD} 56^{-} \mathrm{CD} 161^{+}$cells that were found during in vitro $\mathrm{NK}$ cell differentiation from $\mathrm{CD} 34^{+}$ Lin $^{-}$umbilical cord blood (UCB) cells. ${ }^{35}$ Although IL-15 is known to be indispensable for NK cell development, ${ }^{36,37}$ the generation of pNKs from HSCs is likely an IL-15-independent mechanism. ${ }^{38}$ IL-15 and its specific receptor, IL-15R, mediate NK cell development from committed pNKs and promote their differentiation into iNK cells. ${ }^{39}$

The final maturation of NK cells is characterized by the acquisition of activating and inhibitory receptor expression. The activating receptor NKp44 is the first NK cell receptor to be expressed at the early stage of NK cell maturation. The NKp46, NKp30, NKG2D and DNAM-1 activating receptors are acquired at a later stage. The first inhibitory receptor to be expressed during in vitro NK cell differentiation is CD94/ NKG2A. ${ }^{8}$ The NK cell maturation process also includes the MHC class I-induced NK 'education' or 'licensing' that involves the recognition of self-MHC class I molecules by cognate inhibitory receptors such as KIRs. ${ }^{40,41}$ Further steps of NK cell maturation are required for the acquisition of the cytolytic machinery, such as perforin and granzymes. ${ }^{42}$

\section{Factors involved in NK differentiation}

Although the developmental pathways of NK cells are relatively unclear compared with that of $\mathrm{T}$ and $\mathrm{B}$ lymphocytes, the process of NK cell differentiation seems to be a coordinated mechanism that involves many cytokines, surface receptors and transcription factors.

The BM microenvironment is a major source of cytokines that initiates and facilitates NK differentiation. Within the BM, stromal cells assist the full maturation of $\mathrm{NK}$ cells, ${ }^{43,44}$ suggesting that the BM stroma itself is one of the critical factors for the differentiation of NK cells. Although the intact $\mathrm{BM}$ microenvironment is essential for NK differentiation, the stromal cell requirement might be replaced, at least partially, by early-acting cytokines, including stem cell factor, Flt3L and IL$7,{ }^{32,45}$ that induce CD122 responsiveness through their receptors on pNKs.

Transcription factors are also involved in controlling the NK cell differentiation process. The Ets family (for example, PU.1 and Ets-1) and the Ikaros family (for example, Ikaros, Helios and Aiolos) ${ }^{46-48}$ are essential for the generation of NK cells in vivo by the specification or maintenance of pNKs. The inhibitors of DNA binding (Id proteins) including ID2 and ID $3,{ }^{49}$ as well as E4BP4, ${ }^{50}$ also regulate cell-fate decisions in the early stage of NK development. In addition, we have reported that VDUP-1 (vitamin D3 upregulated protein 1), a stressresponse gene, regulates NK differentiation by controlling both CD122 expression and IL-15 responsiveness. ${ }^{51}$ Transcription factors, including Gata-3, ${ }^{52}$ IRF- $2,{ }^{53}$ and Tox, ${ }^{6,54}$ are involved in the final maturation of NK cells; thus, their absence leads to the incomplete development of functional NK cells or immature phenotypes of NK cells. The acquisition of mature NK cell function is also related to the presence of Eomesodermin (EOMES) and T cell-specific T-box transcription factor (T-bet) 55 that induce the expression of the cytolytic machinery (for example, perforin and granzymes) and interferon- $\gamma ., 54,56$

\section{Production of NK cells in vitro}

Recently, NK cell immunotherapy has been developing rapidly. Achieving NK cell immunotherapy for cancer requires not only an adequate number of NK cells but also NK cell purity and functional activity. Human NK cells can be obtained either directly or indirectly from various sources, such as peripheral blood (PB), UCB, BM, embryonic stem cells (hESCs) or induced pluripotent stem cells (iPSCs). ${ }^{29}$ 
NK cell generation efficiency from $P B$ or UCB. NK cells can be directly isolated from $\mathrm{PB}$ or UCB and expanded for short or long periods of time in vitro and subsequently infused for cancer treatment. Several protocols have been developed for the expansion of PB NK cells for clinical studies. ${ }^{57}$ Purified PB NK cells have been expanded using various feeder cells, such as autologous irradiated feeder cells and third-party Epstein-Barr virus-transformed lymphoblastoid B cell lines. ${ }^{58,59}$ In addition, genetically modified K562 cells, including K562 cells transduced with IL-21, ${ }^{60}$ or K562 cells double transduced with IL-15 and 4-1BB (CD137) ligand (K562-mb15-41BBL), ${ }^{61}$ have been used as feeder cells for NK co-culture systems. The main advantage of these methods is the immediate availability of the cells after long-term expansion in vitro compared with the de novo production of NK cells. However, the prolonged exposure of NK cells to cytokines in vitro induces cell exhaustion that may lead to a low functional activity of NK cells. Moreover, the complete removal of any residual viable tumor feeder in final cell products should be required for NK cell immunotherapy.

Alternatively, NK cells can be selectively isolated from UCB, which is considered a good source for cell therapy. Positively isolated cord blood NK cells cultured on a feeder layer of mesenchymal stromal cells using a combination of IL-2, IL-15, Flt3L and IL-3 achieved an $\sim 60$-fold expansion. ${ }^{62}$ However, because of the low initial numbers of NK cells in UCB, this is not a feasible approach for generating the cell numbers required for application in NK cell therapy. To overcome the obstacles in directly isolating NK cells from fresh samples, NK cells can be generated from CD $34^{+}$HSCs in vitro. Generating $\mathrm{NK}$ cells from $\mathrm{CD} 34^{+}$stem cells can be advantageous because stem cells can be isolated and frozen. Furthermore, NK cells can be manipulated during the process of differentiation from HSCs in vitro. ${ }^{63}$

NK cell generation from UCB CD34 ${ }^{+}$stem cells. It has been shown that NK cells are originated from the $\mathrm{CD} 34^{+}$stem cell compartment in vivo. ${ }^{64}$ Therefore, NK cells can be generated in vitro from $\mathrm{CD} 34^{+} \mathrm{HSC}$ from $\mathrm{BM}^{33,45}$ or $\mathrm{UCB}^{65,66}$ using different combinations of cytokines, BM stromal cells and culture media supplemented with animal or human sera. However, these culture systems contain components of animal origin and fail to produce significant numbers of NK cells. Kao et al. ${ }^{67}$ demonstrated that using fetal bovine serum, UCB $\mathrm{CD} 34^{+}$cells differentiated into NK cells with a purity of $40-60 \%$, finally reaching a 300 -fold expansion. Using complete medium containing human serum, fetal bovine serum and cytokines including IL-15 and IL-21, methylprednisolone has been shown to induce the rapid differentiation of CD $34^{+}$HSCs into NK cells, attaining a 10-fold expansion of NK cells. ${ }^{68}$ In addition, Spanholtz et al. ${ }^{69,70}$ developed a novel cell culture technique for the ex vivo expansion and differentiation of NK cells from UCB CD $34^{+}$cells in the absence of feeder cells using a serum-free culture medium coupled with a mixture of heparin and cytokines that mimic the extracellular matrix of the $\mathrm{BM}$ microenvironment. In this protocol, up to $10^{10} \mathrm{CD} 34^{+}$ cell-derived NK cells without T-cell contamination could be generated. However, a transplantation study using nonobese diabetic/severe combined immunodeficiency mice receiving human HSCs demonstrated that NK cell differentiation from UCB CD $34^{+}$cells was slower and less efficient than NK cell differentiation from $\mathrm{BM} \mathrm{CD} 34^{+}$cells. $^{66}$ Furthermore, that study also demonstrated that $\mathrm{UCB} \mathrm{CD} 34^{+}$cells differentiated into NK cells lacking the expression of KIRs, including CD158a (KIR2DL1), CD158b (KIR2DL2/DL3) and NKB1. ${ }^{66}$ Co-culture with the feeder layer EL08.1D2 has shown that UCB CD34 ${ }^{+}$ -derived NK cells acquired the coordinated NK cell receptors that represent cytotoxic CD56 ${ }^{+}$cells. $^{71}$

NK cell generation from $B M$ or mobilized $P B$. Because NK cells are developed in the BM microenvironment in vivo, the $\mathrm{BM}$ may be a rich source of $\mathrm{CD} 34^{+}$stem cells. NK cells with mature properties have been successfully generated using sorted $\mathrm{CD} 34^{+}$cells from the BM. ${ }^{28,45}$ The main disadvantages of working with BM stem cells are the limitations in cell number and the painful procedure of harvesting cells. To facilitate harvesting, stem cells can alternatively be mobilized using the granulocyte colony-stimulating factor. ${ }^{72}$ Giuliani et al. $^{73}$ generated differentiated NK cells from mobilized PB stem cells to study the effect of membrane-bound IL-15. In 2010, we developed a protocol for generating NK cells using isolated $\mathrm{CD} 34^{+}$cells from mobilized PB for clinical trials and performed allogeneic NK cell transfer after haploidentical hematopoietic stem cell transplantation (HSCT) ${ }^{74}$ Recently, we also developed a novel protocol for the generation of NK cells using T cell-depleted mononuclear cells from mobilized PB that allows for a shorter time period of differentiation and the generation of increased NK cell numbers compared with the earlier protocol. ${ }^{75}$

NK cell generation from hESCs. Because hESCs or iPSCs can give rise to $\mathrm{CD} 34^{+} \mathrm{HSCs}$, they may serve as a source for NK cell differentiation. ${ }^{76}$ Knorr et al. ${ }^{77}$ engineered $\mathrm{CD} 34^{+}$cells, hESCs or iPSCs that expressed chimeric antigen receptors (CARs) specific for tumor-associated antigens for immunotherapy. However, the generation of NK cells from hESCs and iPSCs is still in the experimental phase, and the generation of CD $34^{+}$HSCs from hESCs and iPSCs for hESC- and iPSCbased NK cell therapies still requires optimization. ${ }^{77-79}$

In summary, the methods for NK cell production in vitro for application in immunotherapy are shown in Figure 2.

\section{NK CELL THERAPY}

Because of their ability to recognize and lyse broad range of tumor cells without prior priming, NK cells emerged as promising candidates for cancer therapy. Because NK cells are found primarily in the blood, NK therapy has been most successful in hematopoietic malignancies, such as leukemias. NK cell immunotherapy can be achieved by either activating endogenous NK cell response by administering NK stimulants or using exogenous NK cells via HSCT or adoptive cell transfer. Several strategies for NK cell immunotherapies for human cancer have been proposed. ${ }^{10}$ 


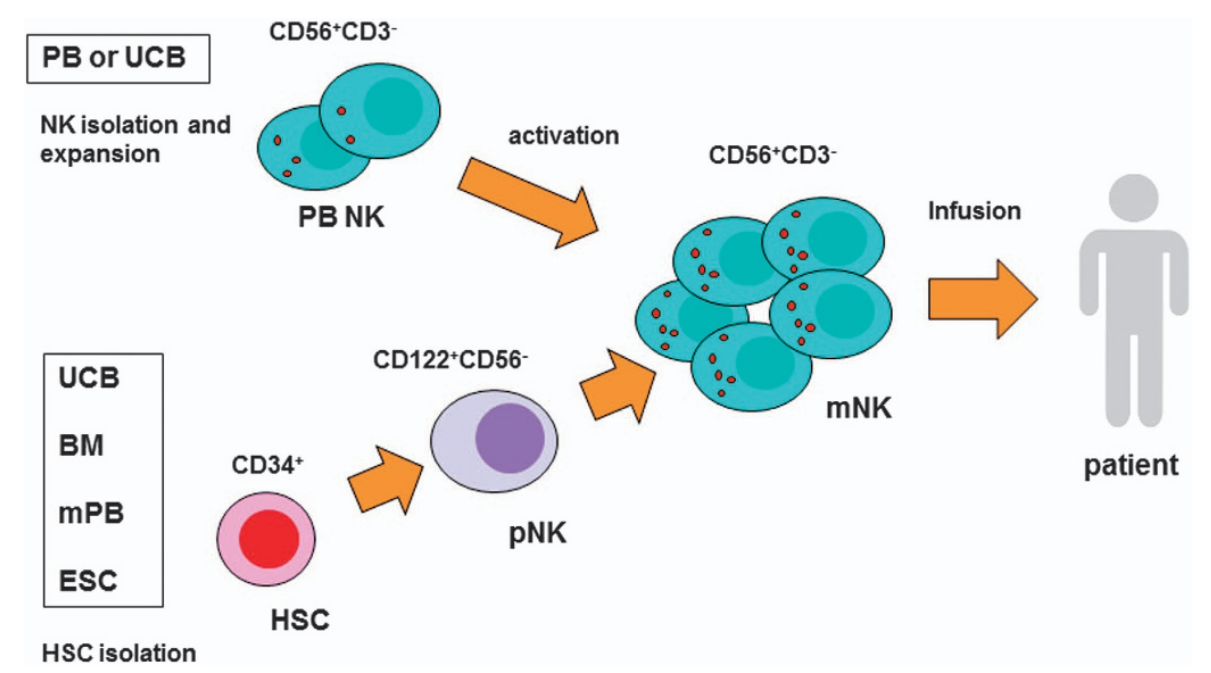

Figure 2 Production of natural killer (NK) cells in vitro for immunotherapy. Human NK cells can be obtained from various sources, such as peripheral blood (PB), umbilical cord blood (UCB), bone marrow (BM), mobilized PB (mPB) or embryonic stem cells (ESCs). NK cells can be isolated from PB or UCB and expanded. In addition, NK cells can be generated using CD34+ hematopoietic stem cells (HSCs) from UCB, BM, mPB or ESCs. CD34+ HSCs are differentiated into $\mathrm{CD}^{+} 6^{+}$mature NK cells (mNK) via CD122 $2^{+}$precursor NK cells ( $p$ NK). Finally, $\mathrm{mNK}$ cells armed with effector functions are infused into the patient for adoptive immunotherapy.

\section{Activation of endogenous NK cell response}

Nonfunctional NK cells are frequently found in cancer patients; thus, exogenous NK activators may be used to enhance the endogenous NK response to tumors. Cytokines, including IL-2, IL-12, IL-15, IL-18, IL-21 and type I interferons, have been used to activate endogenous NK cells both directly and indirectly. ${ }^{80,81}$ The administration of IL-2 has been shown to activate and expand NK cell populations in some cancer patients, ${ }^{82,83}$ although IL-2 treatment is limited by severe side effects. To reduce the side effects of IL-2, combination therapy using IL-2 together with IL-12 and IL-21 has been proposed. ${ }^{84}$ IL-15 is a promising candidate for activating NK cells because IL-15 is indispensable for NK cell maturation. When combined with chemotherapy, the administration of IL-15 potentiated antitumor effects. ${ }^{85}$ In addition, several immunomodulators have been shown to increase the activity of NK cells against tumor cells. For example, thalidomide and lenalidomide increased the number of peripheral blood NK cells and activated NK function against myeloma cells that may be mediated through the stimulation of IL-2 production by $\mathrm{T}$ cells. ${ }^{86-88}$ Similarly, the adjuvant intravesical bacillus CalmetteGuerin $^{89}$ and $\mathrm{CpG}$ oligodeoxynucleotides ${ }^{40}$ have been used to enhance antitumor activity in superficial bladder cancer and non-Hodgkin's lymphoma, respectively. Bortezomib, a proteasome inhibitor, has also been applied to increase the susceptibility of tumor cells by the upregulation of death receptors that trigger cytolysis by NK cells. ${ }^{90}$

\section{NK cell adoptive immunotherapy}

Adoptive immunotherapy refers to the introduction of ex vivomanipulated cells to patients for clinical applications. NK cells can be isolated, expanded or produced in vitro to be transferred in an autologous or allogeneic setting. The first trial involving adoptive transfer of NK cells for antitumor therapy was performed by Rosenberg ${ }^{91}$ using a combination of ex vivoexpanded autologous lymphokine-activated killer cells and exogenous IL-2. However, this trial induced only a $20 \%$ response, including partial and complete responses, a rate similar to the antitumor effect achieved by the administration of high-dose IL-2 alone. $^{92}$

Unlike autologous cell transfers, allogeneic adoptive cell transfers have the benefit of mismatched KIR/KIR ligands between the host and donor NK cells, although these therapies run a great risk of graft-versus-host disease (GVHD) that can cause severe damage to host tissues. Ruggeri et al. ${ }^{93}$ first identified a correlation between donor KIR and host KIR ligand expression in the occurrence of tumor relapse. Compared with KIR-matched transplants, KIR mismatches, in which donor NK cells express KIRs that have no ligand in the patient, produced graft-versus-tumor (GVT) effects in acute myeloid leukemia (AML) patients. In 2005, Miller et al. ${ }^{94}$ performed a combined therapy of haploidentical NK cell infusion together with IL-2 administration for AML patients in a nontransplantation setting. This study demonstrated the safety and efficacy of adoptively transferred human NK cells, with $26 \%$ of AML patients achieving complete remission. An infusion of haploidentical allogeneic NK cells has also been applied to patients with poor prognosis in Hodgkin's lymphoma ${ }^{95}$ and various solid tumors, such as melanoma and renal cancer. ${ }^{96}$ Another approach of adoptive immunotherapy using the NK lymphoma-derived cell line NK-92 has been proposed, although limited data exist on the efficacy of this approach. ${ }^{97}$ To date, the adoptive transfer therapy of NK cells can be applied either alone or in combination with allogeneic stem cell transplantation by donor lymphocyte infusion (DLI). 


\section{Hematopoietic stem cell transplantation}

HSCT is a therapy that is often applied for hematological malignancies and can be classified as autologous or allogeneic depending on the source of the donor cells. Currently, allogeneic stem cell transplantation from unrelated or sibling donors have been used for several hematological malignancies, such as AML and acute lymphoblast leukemia. ${ }^{63,93}$

Allogeneic HSCT requires a human leukocyte antigen (HLA)-mismatched donor from which BM cells are harvested and infused into the patient. Because $\mathrm{T}$ cell receptors are highly individualized and sensitive to non-self presentation, recipient antigen-presenting cells such as dendritic cells may aberrantly activate donor-derived $\mathrm{T}$ cells. In the recipient, these activated $\mathrm{T}$ cells mediate the severe damage characteristic of GVHD. Conversely, donor-derived $\mathrm{T}$ cells also recognize and kill residual tumor cells in the recipient, referred to as the GVT or the graft-versus-leukemia effect. The current strategies used to improve the outcome of allogeneic HSCT in cancer therapy are focused on minimizing harmful GVDH reactions while maximizing beneficial GVT effects. To reduce the risk of GVHD, T cells are often required to be depleted from donor grafts, eliminating GVHD at the expense of inhibiting GVT effects. ${ }^{98}$ Unlike T cells, NK cells have been demonstrated to enhance GVT effects without the implication of GVHD. ${ }^{99}$

\section{Allogeneic NK cells in stem cell transplantation}

Unfortunately, many patients relapse after HSCT. To prevent relapses in patients after HSCT, DLI can be used to induce potent GVT effect, although DLI may cause $\mathrm{T}$ cell-induced GVHD. To minimize the risk of GVHD, T cell-depleted DLI has been applied. The introduction of $\mathrm{T}$ cell-depleted donor lymphocytes containing alloreactive NK cells improved the survival of patients by enhancing graft-versus-leukemia effect and reducing GVHD. ${ }^{100}$ DLI using purified donor NK cells has been shown to facilitate engraftment and induce GVT effects without contributing to GVHD in haploidentical HSCT. ${ }^{101}$ GVT effects can be mediated by both donor-derived NK cells and NK cells that developed from donor hematopoietic stem cells. ${ }^{102,103}$

Because NK cells can kill normal missing-self targets and respond to target cells expressing foreign MHC class I alleles, NK cell alloreactivity can be beneficially utilized for HSCT. A prerequisite for NK cell alloreactivity is that the recipient must lack one or more KIR ligands present in the donor; thus, the recipient's MHC class I allele must not match the KIR of donor-derived NK cells. Taking advantage of NK cell alloreactivity, allogeneic NK cells can be used in combination with HSCT to suppress GVHD and promote graft-versus-leukemia effect. Allogeneic NK cells from a HLA-mismatched donor can decrease GVHD by killing the recipient antigen-presenting cells (for example, dendritic cells) that may otherwise initiate GVHD and produce the graft-versus-leukemia effect by killing residual cancer cells in the recipient. Furthermore, allogeneic NK cells can directly kill the recipient's $\mathrm{T}$ cells, leading to improved engraftment.
Velardi's group ${ }^{93}$ initially demonstrated that donor-versusrecipient NK cell alloactivity could prevent leukemia relapse in AML patients without increasing the risk of GVHD in haploidentical HSCT. It has also been shown that the infusion of allogeneic KIR ligand-mismatched NK cells improved the survival rate and reduced the relapse rate for haploidentical HSCT in AML patients. ${ }^{93,104}$ Other studies have confirmed a beneficial effect of a KIR-ligand mismatch on the relapse rate and the survival of the recipient. ${ }^{105,106}$ Although allogeneic NK cell products have been optimized for T-cell depletion and NK cell expansion, ${ }^{107}$ clinical standardized protocols for the production of NK cells are still lacking. Recently, our group developed a protocol for allogeneic NK cell production without T-cell contamination for clinical trials. Using this protocol, allogeneic NK cells derived from HLA-mismatched donors were transferred to AML patients after haploidentical transplantation, resulting in reduced relapse rates and increased survival rates in patients. ${ }^{74,75}$

\section{Other clinical strategies for NK cell therapy}

Several other approaches have been developed to enhance the effect of NK cell immunotherapy by selectively blocking or activating NK receptors. ${ }^{108}$ Blocking CD94/NKG2A or inhibitory KIRs of NK cells might reduce the NK inhibitory signal, leading to enhanced NK activity, ${ }^{109}$ whereas upregulating the expression of activating receptors, such as NKG2D on NK cells, or their ligands (ULBPs and MICA/B) on tumor cells, could increase the NK activating signal. ${ }^{110}$ Histone deacetylase inhibitors ${ }^{111,112}$ and heat shock 90 inhibitors $^{113}$ have been shown to upregulate the expression of NKG2D ligands, MICA and MICB on the tumor cells, thereby rendering tumor cells more susceptible to NK cell-mediated cytotoxicity. Treatment of drugs such as melphalan, etoposide and doxorubicin that induce DNA damage responses also increased the susceptibility of myeloma cells to NK cells by upregulating the NK activating ligands, DNAX accessory molecule-1 (DNAM-1) ligand and NKG2D ligand. ${ }^{113}$ Antibodies that block inhibitory receptors can be used to mimic the missing self-environment and augment NK cell-mediated killing. Recently, a human monoclonal antibody, 1-7F9, that prevents signaling via KIR2DL1, KIR2DL2 and KIR2DL3 was developed to increase NK cellmediated cytotoxicity against tumors expressing HLA-C. ${ }^{114,115}$ In addition, bortezomib, a proteasome inhibitor, has been shown to increase NK function by reducing the expression of MHC class I on the surface of myeloma cells. ${ }^{116}$

NK cell effector functions can also be mediated by antibodydependent cellular cytotoxicity. ${ }^{117}$ Because NK cells execute antibody-dependent cellular cytotoxicity through the CD16 (FCR $\mathrm{III}$ ) receptor on their surface, treatment with an antibody can trigger effector functions of NK cells against tumor targets. For example, in $\mathrm{CD} 20^{+}$lymphoma, the administration of the CD20 antibody rituximab induced antibody-dependent cellular cytotoxicity to antibody-coated target cells via binding to the CD16 receptor on the surface of NK cells. ${ }^{118,119}$ Similarly, bispecific antibodies for CD16 on NK cells and for 


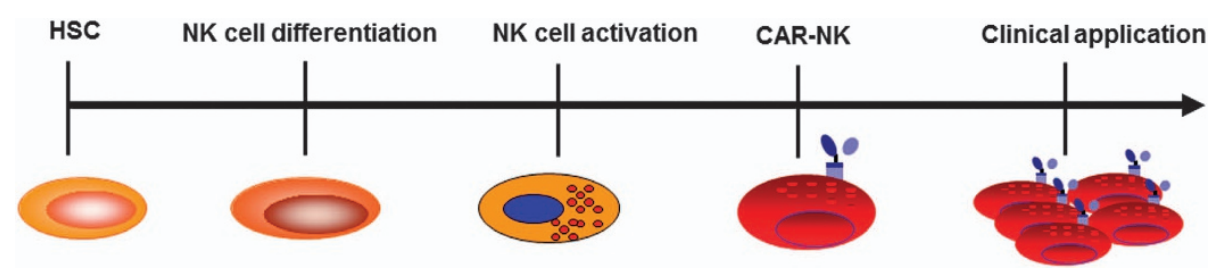

Figure 3 From hematopoietic stem cells (HSCs) to clinical application. Natural killer (NK) cells are differentiated from HSCs. For efficient NK cell therapy, each step of NK cell preparation is important. NK cell differentiation, activation and genetically modified NK cells (chimeric antigen receptor (CAR)-NK) are major strategies for the generation of potent NK cell therapy.

CD30 on non-Hodgkin's lymphoma promoted NK cell recognition and cytolysis of tumor cells. ${ }^{120}$

Genetic engineering of NK cells may also become important in manipulating and enhancing their therapeutic potential. Because $\mathrm{T}$ cells can successfully be genetically engineered to express a CAR for CD19, similar strategies have been developed for NK cells. NK cells transduced with a disialoganglioside GD2-recognizing CAR have been applied to enhance cytotoxicity in neuroblastoma. ${ }^{121}$ Engineering NK cells with CARs specific for CD19 or for CD20 has also been proposed as treatment for leukemias and lymphomas, respectively. ${ }^{54,122}$

\section{CONCLUSION}

NK cells have diverse functions in regulating the innate and adaptive immune responses. These properties are derived from the molecular characteristics of NK cells. They express several different surface receptors that can recognize target cells that have appropriate ligands on their surface. In addition, NK cells can secrete cytokines and soluble factors to regulate other immune cells, such as T cells and dendritic cells.

These functional properties make NK cells applicable for clinical treatment, with several groups achieving limited success. To explore NK cell therapy more effectively, we need to understand NK cell biology and function in detail. NK cells are differentiated from HSCs. At each of the steps in NK cell differentiation, activation and genetic modification (for example, CAR-NK cells) may serve as a critical target for successful clinical applications (Figure 3). In the preparation of NK cells, NK cells must be properly activated, and NK cell subsets should be manipulated depending on the type of disease: NK cells with more cytolytic activity are required for the treatment of cancer, whereas NK cells that secrete interferons will be beneficial for the treatment of viral infections.

Several other issues should be considered for the development of successful NK cell-based immunotherapy. Among them is NK cell preparation, which includes the purity and expansion of NK cells, and the criteria for donor selection (KIR genotypes and alloreactive subset sizes). The optimal doses and timing of administration of NK cells should also be determined. Additional factors for consideration include the optimization of conditioning recipients, enhancement of NK cell function and tumor cell susceptibility.

NK cell therapy can be combined with other immunotherapies, including cytotoxic $\mathrm{T}$ lymphocyte therapy and antibody therapy. Understanding NK cell properties and functions will extend its field of application and enhance its availability to fight diseases in the future.

\section{CONFLICT OF INTEREST}

The authors declare no conflict of interest.

\section{ACKNOWLEDGEMENTS}

This work was supported in part by grants from the GRL project (FGM1401223), the Ministry of Science, ICT \& Future Planning, KRIBB Research Initiative Program, the Korean Health Technology R\&D Project (A121934) and Basic Science Research Program through the National Research Foundation of Korea (RBM0261413 and RBM0271413).

1 Vivier E, Ugolini S, Blaise D, Chabannon C, Brossay L. Targeting natural killer cells and natural killer T cells in cancer. Nat Rev Immunol 2012; 12: 239-252.

2 Vivier E, Ugolini S. Natural killer cells: from basic research to treatments. Front Immunol 2011; 2: 18

3 Romagne F, Vivier E. Natural killer cell-based therapies. F1000 Med Rep 2011; 3: 9.

4 Narni-Mancinelli E, Ugolini S, Vivier E. Tuning the threshold of natural killer cell responses. Curr Opin Immunol 2013; 25: 53-58.

5 Leong JW, Sullivan RP, Fehniger TA. microRNA management of NK-cell developmental and functional programs. Eur J Immunol 2014; 44: 2862-2868.

6 Kim TD, Lee SU, Yun S, Sun HN, Lee SH, Kim JW et al. Human microRNA-27a* targets Prf1 and GzmB expression to regulate NK-cell cytotoxicity. Blood 2011; 118: 5476-5486.

7 Yun S, Lee SH, Yoon SR, Kim MS, Piao ZH, Myung PK et al. TOX regulates the differentiation of human natural killer cells from hematopoietic stem cells in vitro. Immunol Lett 2011; 136: 29-36.

8 Freud AG, Caligiuri MA. Human natural killer cell development. Immunol Rev 2006; 214: 56-72.

9 Malhotra A, Shanker A. NK cells: immune cross-talk and therapeutic implications. Immunotherapy 2011; 3: 1143-1166.

10 Ljunggren HG, Malmberg KJ. Prospects for the use of NK cells in immunotherapy of human cancer. Nat Rev Immunol 2007; 7 329-339.

11 Vivier E, Nunes JA, Vely F. Natural killer cell signaling pathways. Science 2004; 306: 1517-1519.

12 Krzewski K, Strominger JL. The killer's kiss: the many functions of NK cell immunological synapses. Curr Opin Cell Biol 2008; 20: 597-605.

13 Romee R, Leong JW, Fehniger TA. Utilizing cytokines to function-enable human NK cells for the immunotherapy of cancer. Scientifica (Cairo) 2014; 2014: 205796.

14 Fehniger TA, Caligiuri MA. Interleukin 15: biology and relevance to human disease. Blood 2001; 97: 14-32.

15 Lucas M, Schachterle W, Oberle K, Aichele P, Diefenbach A. Dendritic cells prime natural killer cells by trans-presenting interleukin 15. Immunity 2007; 26: 503-517. 
16 Cooper MA, Elliott JM, Keyel PA, Yang L, Carrero JA, Yokoyama WM. Cytokine-induced memory-like natural killer cells. Proc Natl Acad Sci USA 2009; 106: 1915-1919.

17 Roda-Navarro P, Reyburn HT. Intercellular protein transfer at the NK cell immune synapse: mechanisms and physiological significance. FASEB $J$ 2007; 21: 1636-1646.

18 Davis DM, Chiu I, Fassett M, Cohen GB, Mandelboim O, Strominger JL. The human natural killer cell immune synapse. Proc Natl Acad Sci USA 1999; 96: 15062-15067.

19 Orange JS. Formation and function of the lytic NK-cell immunological synapse. Nat Rev Immunol 2008; 8: 713-725.

20 Cao X, Cai SF, Fehniger TA, Song J, Collins LI, Piwnica-Worms DR et al. Granzyme B and perforin are important for regulatory $\mathrm{T}$ cell-mediated suppression of tumor clearance. Immunity 2007; 27: 635-646.

21 Sullivan RP, Leong JW, Schneider SE, Keppel CR, Germino E, French AR et al. MicroRNA-deficient NK cells exhibit decreased survival but enhanced function. J Immunol 2012; 188: 3019-3030.

22 Sullivan RP, Leong JW, Fehniger TA. MicroRNA regulation of natural killer cells. Front Immunol 2013; 4: 44

23 Terme M, Ullrich E, Delahaye NF, Chaput N, Zitvogel L. Natural killer celldirected therapies: moving from unexpected results to successful strategies. Nat Immunol 2008; 9: 486-494.

24 Colucci F, Caligiuri MA, Di Santo JP. What does it take to make a natural killer? Nat Rev Immunol 2003; 3: 413-425.

25 Vacca P, Vitale C, Montaldo E, Conte R, Cantoni C, Fulcheri E et al. CD34 + hematopoietic precursors are present in human decidua and differentiate into natural killer cells upon interaction with stromal cells. Proc Natl Acad Sci USA 2011; 108: 2402-2407.

26 Ikawa T, Kawamoto H, Fujimoto S, Katsura Y. Commitment of common T/ natural killer (NK) progenitors to unipotent $T$ and NK progenitors in the murine fetal thymus revealed by a single progenitor assay. J Exp Med 1999; 190: 1617-1626.

27 Phillips JH, Hori T, Nagler A, Bhat N, Spits H, Lanier LL. Ontogeny of human natural killer (NK) cells: fetal NK cells mediate cytolytic function and express cytoplasmic CD3 epsilon,delta proteins. J Exp Med 1992; 175: 1055-1066.

28 Miller JS, Alley KA, McGlave P. Differentiation of natural killer (NK) cells from human primitive marrow progenitors in a stroma-based long-term culture system: identification of a CD34+7+ NK progenitor. Blood 1994; 83: 2594-2601.

29 Luevano M, Madrigal A, Saudemont A. Generation of natural killer cells from hematopoietic stem cells in vitro for immunotherapy. Cell $\mathrm{Mol}$ Immunol 2012; 9: 310-320.

30 Blom B, Spits H. Development of human lymphoid cells. Annu Rev Immunol 2006; 24: 287-320.

31 Grzywacz B, Kataria N, Kataria N, Blazar BR, Miller JS, Verneris MR. Natural killer-cell differentiation by myeloid progenitors. Blood 2011; 117: 3548-3558.

32 Williams NS, Klem J, Puzanov IJ, Sivakumar PV, Schatzle JD, Bennett M et al. Natural killer cell differentiation: insights from knockout and transgenic mouse models and in vitro systems. Immunol Rev 1998; 165: 47-61.

33 Yu H, Fehniger TA, Fuchshuber P, Thiel KS, Vivier E, Carson WE et al. Flt3 ligand promotes the generation of a distinct CD34(+) human natural killer cell progenitor that responds to interleukin-15. Blood 1998; 92: 3647-3657.

34 Sivori S, Falco M, Marcenaro E, Parolini S, Biassoni R, Bottino C et al. Early expression of triggering receptors and regulatory role of $2 \mathrm{~B} 4$ in human natural killer cell precursors undergoing in vitro differentiation. Proc Natl Acad Sci USA 2002; 99: 4526-4531.

35 Lanier LL, Chang C, Phillips JH. Human NKR-P1A. A disulfide-linked homodimer of the C-type lectin superfamily expressed by a subset of NK and T lymphocytes. J Immunol 1994; 153: 2417-2428.

36 Carson WE, Giri JG, Lindemann MJ, Linett ML, Ahdieh M, Paxton R et al. Interleukin (IL) 15 is a novel cytokine that activates human natural killer cells via components of the IL-2 receptor. J Exp Med 1994; 180: 1395-1403.

37 Cooper MA, Bush JE, Fehniger TA, VanDeusen JB, Waite RE, Liu Y et al. In vivo evidence for a dependence on interleukin 15 for survival of natural killer cells. Blood 2002; 100: 3633-3638.

38 Vosshenrich CA, Ranson T, Samson SI, Corcuff E, Colucci F, Rosmaraki EE et al. Roles for common cytokine receptor gamma-chaindependent cytokines in the generation, differentiation, and maturation of
NK cell precursors and peripheral NK cells in vivo. J Immunol 2005; 174: 1213-1221.

39 Roychowdhury S, Blaser BW, Freud AG, Katz K, Bhatt D, Ferketich AK et al. IL-15 but not IL-2 rapidly induces lethal xenogeneic graft-versushost disease. Blood 2005; 106: 2433-2435.

40 Anfossi N, Andre P, Guia S, Falk CS, Roetynck S, Stewart CA et al. Human NK cell education by inhibitory receptors for MHC class I. Immunity 2006; 25: 331-342.

41 Yokoyama WM, Kim S. Licensing of natural killer cells by self-major histocompatibility complex class I. Immunol Rev 2006; 214: 143-154.

42 Montaldo E, Vacca P, Moretta L, Mingari MC. Understanding human NK cell differentiation: clues for improving the haploidentical hematopoietic stem cell transplantation. Immunol Lett 2013; 155: 2-5.

43 van den Brink MR, Boggs SS, Herberman RB, Hiserodt JC. The generation of natural killer (NK) cells from NK precursor cells in rat long-term bone marrow cultures. J Exp Med 1990; 172: 303-313.

44 Ogasawara K, Hida S, Azimi N, Tagaya Y, Sato T, Yokochi-Fukuda T et al. Requirement for IRF-1 in the microenvironment supporting development of natural killer cells. Nature 1998; 391: 700-703.

45 Mrozek E, Anderson P, Caligiuri MA. Role of interleukin-15 in the development of human CD56+ natural killer cells from CD34+ hematopoietic progenitor cells. Blood 1996; 87: 2632-2640.

46 Warren LA, Rothenberg EV. Regulatory coding of lymphoid lineage choice by hematopoietic transcription factors. Curr Opin Immunol 2003; 15: $166-175$.

47 Colucci F, Samson SI, DeKoter RP, Lantz O, Singh H, Di Santo JP. Differential requirement for the transcription factor PU.1 in the generation of natural killer cells versus B and T cells. Blood 2001; 97: 2625-2632.

48 Boggs SS, Trevisan M, Patrene K, Geogopoulos K. Lack of natural killer cell precursors in fetal liver of Ikaros knockout mutant mice. Nat Immun 1998; 16: 137-145

49 Spits $\mathrm{H}$, Couwenberg F, Bakker AQ, Weijer K, Uittenbogaart $\mathrm{CH}$. Id2 and Id3 inhibit development of CD34(+) stem cells into predendritic cell (preDC)2 but not into pre-DC1. Evidence for a lymphoid origin of pre-DC2. J Exp Med 2000; 192: 1775-1784.

50 Kamizono S, Duncan GS, Seidel MG, Morimoto A, Hamada K, Grosveld G et al. Nfil3/E4bp4 is required for the development and maturation of NK cells in vivo. J Exp Med 2009; 206: 2977-2986.

51 Lee KN, Kang HS, Jeon JH, Kim EM, Yoon SR, Song H et al. VDUP1 is required for the development of natural killer cells. Immunity 2005; 22: 195-208.

52 Samson SI, Richard O, Tavian M, Ranson T, Vosshenrich CA, Colucci F et al. GATA-3 promotes maturation, IFN-gamma production, and liverspecific homing of NK cells. Immunity 2003; 19: 701-711.

53 Lohoff M, Duncan GS, Ferrick D, Mittrucker HW, Bischof S, Prechtl S et al. Deficiency in the transcription factor interferon regulatory factor (IRF)-2 leads to severely compromised development of natural killer and T helper type 1 cells. J Exp Med 2000; 192: 325-336.

54 Aliahmad P, de la Torre B, Kaye J. Shared dependence on the DNAbinding factor TOX for the development of lymphoid tissue-inducer cell and NK cell lineages. Nat Immunol 2010; 11: 945-952.

55 Townsend MJ, Weinmann AS, Matsuda JL, Salomon R, Farnham PJ, Biron CA et al. T-bet regulates the terminal maturation and homeostasis of NK and Valpha14i NKT cells. Immunity 2004; 20: 477-494.

56 Gascoyne DM, Long E, Veiga-Fernandes H, de Boer J, Williams O, Seddon B et al. The basic leucine zipper transcription factor E4BP4 is essential for natural killer cell development. Nat Immunol 2009; 10: 1118-1124.

57 Koepsell SA, Miller JS, McKenna DH Jr. Natural killer cells: a review of manufacturing and clinical utility. Transfusion 2013; 53: 404-410.

58 Siegler U, Meyer-Monard S, Jorger S, Stern M, Tichelli A, Gratwohl A et al. Good manufacturing practice-compliant cell sorting and large-scale expansion of single KIR-positive alloreactive human natural killer cells for multiple infusions to leukemia patients. Cytotherapy 2010; 12 : 750-763.

59 Berg M, Lundqvist A, McCoy P Jr, Samsel L, Fan Y, Tawab A et al. Clinical-grade ex vivo-expanded human natural killer cells up-regulate activating receptors and death receptor ligands and have enhanced cytolytic activity against tumor cells. Cytotherapy 2009; 11: 341-355.

60 Gong W, Xiao W, Hu M, Weng X, Qian L, Pan X et al. Ex vivo expansion of natural killer cells with high cytotoxicity by $\mathrm{K} 562$ cells modified to coexpress major histocompatibility complex class I chain-related protein $A$, 4-1BB ligand, and interleukin-15. Tissue Antigens 2010; 76: 467-475. 
61 Fujisaki H, Kakuda H, Shimasaki N, Imai C, Ma J, Lockey T et al. Expansion of highly cytotoxic human natural killer cells for cancer cell therapy. Cancer Res 2009; 69: 4010-4017.

62 Boissel L, Tuncer HH, Betancur M, Wolfberg A, Klingemann H. Umbilical cord mesenchymal stem cells increase expansion of cord blood natural killer cells. Biol Blood Marrow Transplant 2008; 14: 1031-1038.

63 Shlomchik WD, Couzens MS, Tang CB, McNiff J, Robert ME, Liu J et al. Prevention of graft versus host disease by inactivation of host antigenpresenting cells. Science 1999; 285: 412-415.

64 Di Santo JP. Natural killer cell developmental pathways: a question of balance. Annu Rev Immunol 2006; 24: 257-286.

65 Carayol G, Robin C, Bourhis JH, Bennaceur-Griscelli A, Chouaib S, Coulombel $\mathrm{L}$ et al. NK cells differentiated from bone marrow, cord blood and peripheral blood stem cells exhibit similar phenotype and functions. Eur J Immunol 1998; 28: 1991-2002.

66 Kalberer CP, Siegler U, Wodnar-Filipowicz A. Human NK cell development in NOD/SCID mice receiving grafts of cord blood CD34+ cells. Blood 2003; 102: 127-135.

67 Kao IT, Yao CL, Kong ZL, Wu ML, Chuang TL, Hwang SM. Generation of natural killer cells from serum-free, expanded human umbilical cord blood CD34+ cells. Stem Cells Dev 2007; 16: 1043-1051.

68 Vitale C, Cottalasso F, Montaldo E, Moretta L, Mingari MC. Methylprednisolone induces preferential and rapid differentiation of CD34+ cord blood precursors toward NK cells. Int Immunol 2008; 20: 565-575.

69 Spanholtz J, Tordoir M, Eissens D, Preijers F, van der Meer A, Joosten I et al. High log-scale expansion of functional human natural killer cells from umbilical cord blood CD34-positive cells for adoptive cancer immunotherapy. PLoS One 2010; 5: e9221.

70 Spanholtz J, Preijers F, Tordoir M, Trilsbeek C, Paardekooper J, de Witte T et al. Clinical-grade generation of active NK cells from cord blood hematopoietic progenitor cells for immunotherapy using a closed-system culture process. PLoS One 2011; 6: e20740.

71 Grzywacz B, Kataria N, Sikora M, Oostendorp RA, Dzierzak EA, Blazar BR et al. Coordinated acquisition of inhibitory and activating receptors and functional properties by developing human natural killer cells. Blood 2006; 108: 3824-3833.

72 Petit I, Szyper-Kravitz M, Nagler A, Lahav M, Peled A, Habler L et al. GCSF induces stem cell mobilization by decreasing bone marrow SDF-1 and up-regulating CXCR4. Nat Immunol 2002; 3: 687-694.

73 Giuliani M, Giron-Michel J, Negrini S, Vacca P, Durali D, Caignard A et al. Generation of a novel regulatory NK cell subset from peripheral blood CD34+ progenitors promoted by membrane-bound IL-15. PLoS One 2008; 3: e2241.

74 Yoon SR, Lee YS, Yang SH, Ahn KH, Lee JH, Lee JH et al. Generation of donor natural killer cells from CD34(+) progenitor cells and subsequent infusion after HLA-mismatched allogeneic hematopoietic cell transplantation: a feasibility study. Bone Marrow Transplant 2010; 45: 1038-1046.

75 Choi I, Yoon SR, Park SY, Kim H, Jung SJ, Jang YJ et al. Donor-derived natural killer cells infused after human leukocyte antigen-haploidentical hematopoietic cell transplantation: a dose-escalation study. Biol Blood Marrow Transplant 2014; 20: 696-704.

76 Kaufman DS, Hanson ET, Lewis RL, Auerbach R, Thomson JA. Hematopoietic colony-forming cells derived from human embryonic stem cells Proc Natl Acad Sci USA 2001; 98: 10716-10721.

77 Knorr DA, Kaufman DS. Pluripotent stem cell-derived natural killer cells for cancer therapy. Trans/ Res 2010; 156: 147-154.

78 Kaufman DS. Toward clinical therapies using hematopoietic cells derived from human pluripotent stem cells. Blood 2009; 114: 3513-3523.

79 Woll PS, Grzywacz B, Tian X, Marcus RK, Knorr DA, Verneris MR et al. Human embryonic stem cells differentiate into a homogeneous population of natural killer cells with potent in vivo antitumor activity. Blood 2009; 113: 6094-6101.

80 Smyth MJ, Cretney E, Kershaw MH, Hayakawa Y. Cytokines in cancer immunity and immunotherapy. Immunol Rev 2004; 202: 275-293.

81 Becknell B, Caligiuri MA. Interleukin-2, interleukin-15, and their roles in human natural killer cells. Adv Immunol 2005; 86: 209-239.

82 Farag SS, Caligiuri MA. Cytokine modulation of the innate immune system in the treatment of leukemia and lymphoma. Adv Pharmacol 2004; 51 295-318.

83 Rosenberg SA. Interleukin-2 and the development of immunotherapy for the treatment of patients with cancer. Cancer J Sci Am 2000; 6(Suppl 1): S2-S7.
84 Weiss JM, Subleski JJ, Wigginton JM, Wiltrout RH. Immunotherapy of cancer by IL-12-based cytokine combinations. Expert Opin Biol Ther 2007; 7: 1705-1721.

85 Jakobisiak M, Golab J, Lasek W. Interleukin 15 as a promising candidate for tumor immunotherapy. Cytokine Growth Factor Rev 2011; 22: 99-108.

86 Hayashi T, Hideshima T, Akiyama M, Podar K, Yasui H, Raje N et al. Molecular mechanisms whereby immunomodulatory drugs activate natural killer cells: clinical application. Br J Haematol 2005; 128: 192-203.

87 Tai YT, Li XF, Catley L, Coffey R, Breitkreutz I, Bae J et al. Immunomodulatory drug lenalidomide (CC-5013, IMiD3) augments anti-CD40 SGN-40-induced cytotoxicity in human multiple myeloma: clinical implications. Cancer Res 2005; 65: 11712-11720.

88 Hsu AK, Quach H, Tai T, Prince HM, Harrison SJ, Trapani JA et al. The immunostimulatory effect of lenalidomide on NK-cell function is profoundly inhibited by concurrent dexamethasone therapy. Blood 2011; 117: 1605-1613.

89 Brandau S, Riemensberger J, Jacobsen M, Kemp D, Zhao W, Zhao X et al. NK cells are essential for effective BCG immunotherapy. Int J Cancer 2001; 92: 697-702.

90 Ames E, Hallett WH, Murphy WJ. Sensitization of human breast cancer cells to natural killer cell-mediated cytotoxicity by proteasome inhibition. Clin Exp Immunol 2009; 155: 504-513.

91 Rosenberg S. Lymphokine-activated killer cells: a new approach to immunotherapy of cancer. J Natl Cancer Inst 1985; 75: 595-603.

92 Rosenberg SA, Lotze MT, Muul LM, Chang AE, Avis FP, Leitman S et al. A progress report on the treatment of 157 patients with advanced cancer using lymphokine-activated killer cells and interleukin-2 or high-dose interleukin-2 alone. N Engl J Med 1987; 316: 889-897.

93 Ruggeri L, Capanni M, Urbani E, Perruccio K, Shlomchik WD, Tosti A et al. Effectiveness of donor natural killer cell alloreactivity in mismatched hematopoietic transplants. Science 2002; 295: 2097-2100.

94 Miller JS, Soignier Y, Panoskaltsis-Mortari A, McNearney SA, Yun GH, Fautsch SK et al. Successful adoptive transfer and in vivo expansion of human haploidentical NK cells in patients with cancer. Blood 2005; 105 3051-3057.

95 Bachanova V, Burns LJ, McKenna DH, Curtsinger J, Panoskaltsis-Mortari A, Lindgren BR et al. Allogeneic natural killer cells for refractory lymphoma. Cancer Immunol Immunother 2010; 59: 1739-1744.

96 Geller MA, Cooley S, Judson PL, Ghebre R, Carson LF, Argenta PA et al. A phase II study of allogeneic natural killer cell therapy to treat patients with recurrent ovarian and breast cancer. Cytotherapy 2011; 13: 98-107.

97 Arai S, Meagher R, Swearingen M, Myint H, Rich E, Martinson J et al. Infusion of the allogeneic cell line NK-92 in patients with advanced renal cell cancer or melanoma: a phase I trial. Cytotherapy 2008; 10 625-632.

98 Welniak LA, Blazar BR, Murphy WJ. Immunobiology of allogeneic hematopoietic stem cell transplantation. Annu Rev Immunol 2007; 25 139-170.

99 Barao I, Murphy WJ. The immunobiology of natural killer cells and bone marrow allograft rejection. Biol Blood Marrow Transplant 2003; 9 727-741.

100 Soiffer RJ, Alyea EP, Hochberg E, Wu C, Canning C, Parikh B et al. Randomized trial of $\mathrm{CD} 8+\mathrm{T}$-cell depletion in the prevention of graftversus-host disease associated with donor lymphocyte infusion. Biol Blood Marrow Transplant 2002; 8: 625-632.

101 Passweg JR, Tichelli A, Meyer-Monard S, Heim D, Stern M, Kuhne T et al. Purified donor NK-lymphocyte infusion to consolidate engraftment after haploidentical stem cell transplantation. Leukemia 2004; 18 $1835-1838$

102 Ruggeri L, Mancusi A, Burchielli E, Aversa F, Martelli MF, Velardi A. Natural killer cell alloreactivity and haplo-identical hematopoietic transplantation. Cytotherapy 2006; 8: 554-558.

103 Ruggeri L, Mancusi A, Capanni M, Urbani E, Carotti A, Aloisi T et al. Donor natural killer cell allorecognition of missing self in haploidentical hematopoietic transplantation for acute myeloid leukemia: challenging its predictive value. Blood 2007; 110: 433-440.

104 Ruggeri L, Mancusi A, Perruccio K, Burchielli E, Martelli MF, Velardi A Natural killer cell alloreactivity for leukemia therapy. J Immunother 2005 28: 175-182.

105 Giebel S, Locatelli F, Lamparelli T, Velardi A, Davies S, Frumento G et al. Survival advantage with KIR ligand incompatibility in hematopoietic stem cell transplantation from unrelated donors. Blood 2003; 102: 814-819. 
106 Miller JS, Cooley S, Parham P, Farag SS, Verneris MR, McQueen KL et al. Missing KIR ligands are associated with less relapse and increased graftversus-host disease (GVHD) following unrelated donor allogeneic HCT. Blood 2007; 109: 5058-5061.

107 Koehl U, Brehm C, Huenecke S, Zimmermann SY, Kloess S, Bremm M et al. Clinical grade purification and expansion of NK cell products for an optimized manufacturing protocol. Front Oncol 2013; 3: 118.

108 Sentman CL, Barber MA, Barber A, Zhang T. NK cell receptors as tools in cancer immunotherapy. Adv Cancer Res 2006; 95: 249-292.

109 Long EO, Barber DF, Burshtyn DN, Faure M, Peterson M, Rajagopalan S et al. Inhibition of natural killer cell activation signals by killer cell immunoglobulin-like receptors (CD158). Immunol Rev 2001; 181: 223-233.

110 Sutherland CL, Rabinovich B, Chalupny NJ, Brawand P, Miller R, Cosman D. ULBPS, human ligands of the NKG2D receptor, stimulate tumor immunity with enhancement by IL-15. Blood 2006; 108: 1313-1319.

111 Skov S, Rieneck K, Bovin LF, Skak K, Tomra S, Michelsen BK et al. Histone deacetylase inhibitors: a new class of immunosuppressors targeting a novel signal pathway essential for CD154 expression. Blood 2003; 101: 1430-1438.

112 Diermayr S, Himmelreich H, Durovic B, Mathys-Schneeberger A, Siegler $U$, Langenkamp $U$ et al. NKG2D ligand expression in AML increases in response to HDAC inhibitor valproic acid and contributes to allorecognition by NK-cell lines with single KIR-HLA class I specificities. Blood 2008; 111: 1428-1436.

113 Fionda C, Soriani A, Malgarini G, lannitto ML, Santoni A, Cippitelli M. Heat shock protein-90 inhibitors increase MHC class I-related chain A and $B$ ligand expression on multiple myeloma cells and their ability to trigger NK cell degranulation. J Immunol 2009; 183: 4385-4394.

114 Romagne F, Andre P, Spee P, Zahn S, Anfossi N, Gauthier L et al. Preclinical characterization of 1-7F9, a novel human anti-KIR receptor therapeutic antibody that augments natural killer-mediated killing of tumor cells. Blood 2009; 114: 2667-2677.

115 Benson DM Jr., Bakan CE, Zhang S, Collins SM, Liang J, Srivastava S et al. IPH2101, a novel anti-inhibitory KIR antibody, and lenalidomide combine to enhance the natural killer cell versus multiple myeloma effect. Blood 2011; 118: 6387-6391.

116 Shi J, Tricot GJ, Garg TK, Malaviarachchi PA, Szmania SM, Kellum RE et al. Bortezomib down-regulates the cell-surface expression of HLA class I and enhances natural killer cell-mediated lysis of myeloma. Blood 2008; 111: 1309-1317.

117 Weiner GJ. Rituximab: mechanism of action. Semin Hematol 2010; 47: 115-123.

118 Dall'Ozzo S, Tartas S, Paintaud G, Cartron G, Colombat P, Bardos P et al. Rituximab-dependent cytotoxicity by natural killer cells: influence of FCGR3A polymorphism on the concentration-effect relationship. Cancer Res 2004; 64: 4664-4669.

119 Marcus R, Hagenbeek A. The therapeutic use of rituximab in nonHodgkin's Iymphoma. Eur J Haematol Suppl 20075-14.

120 Hartmann F, Renner C, Jung W, da Costa L, Tembrink S, Held G et al. Anti-CD16/CD30 bispecific antibody treatment for Hodgkin's disease: role of infusion schedule and costimulation with cytokines. Clin Cancer Res 2001; 7: 1873-1881.

121 Esser R, Muller T, Stefes D, Kloess S, Seidel D, Gillies SD et al. NK cells engineered to express a GD2 -specific antigen receptor display built-in
ADCC-like activity against tumour cells of neuroectodermal origin. J Cell Mol Med 2012; 16: 569-581.

122 Muller T, Uherek C, Maki G, Chow KU, Schimpf A, Klingemann HG et al. Expression of a CD20-specific chimeric antigen receptor enhances cytotoxic activity of NK cells and overcomes NK-resistance of Iymphoma and leukemia cells. Cancer Immunol Immunother 2008; 57: 411-423.

123 Bezman NA, Chakraborty T, Bender T, Lanier LL. miR-150 regulates the development of NK and iNKT cells. J Exp Med 2011; 208: 2717-2731.

124 Kim N, Kim M, Yun S, Doh J, Greenberg PD, Kim TD et al. MicroRNA-150 regulates the cytotoxicity of natural killers by targeting perforin-1. J Allergy Clin Immunol 2014; 134: 195-203.

125 Fehniger TA, Wylie T, Germino E, Leong JW, Magrini VJ, Koul S et al. Next-generation sequencing identifies the natural killer cell microRNA transcriptome. Genome Res 2010; 20: 1590-1604.

126 Wang $P$, Gu Y, Zhang Q, Han Y, Hou J, Lin L et al. Identification of resting and type I IFN-activated human NK cell miRNomes reveals microRNA-378 and microRNA-30e as negative regulators of NK cell cytotoxicity. J Immunol 2012; 189: 211-221.

127 Trotta R, Chen L, Ciarlariello D, Josyula S, Mao C, Costinean S et al. miR-155 regulates IFN-gamma production in natural killer cells. Blood 2012; 119: 3478-3485.

128 Zawislak CL, Beaulieu AM, Loeb GB, Karo J, Canner D, Bezman NA et al. Stage-specific regulation of natural killer cell homeostasis and response against viral infection by microRNA-155. Proc Natl Acad Sci USA 2013; 110: 6967-6972.

129 Cichocki F, Felices M, McCullar V, Presnell SR, Al-Attar A, Lutz CT et al. Cutting edge: microRNA-181 promotes human NK cell development by regulating Notch signaling. J Immunol 2011; 187: 6171-6175.

$130 \mathrm{Ma} F$, Xu S, Liu X, Zhang Q, Xu X, Liu M et al. The microRNA miR-29 controls innate and adaptive immune responses to intracellular bacterial infection by targeting interferon-gamma. Nat Immunol 2011; 12: 861-869.

131 Huang $\mathrm{Y}$, Lei $\mathrm{Y}$, Zhang $\mathrm{H}$, Hou L, Zhang $\mathrm{M}$, Dayton Al. MicroRNA regulation of STAT4 protein expression: rapid and sensitive modulation of IL-12 signaling in human natural killer cells. Blood 2011; 118: 6793-6802.

132 Donatelli SS, Zhou JM, Gilvary DL, Eksioglu EA, Chen X, Cress WD et al. TGF-beta-inducible microRNA-183 silences tumor-associated natural killer cells. Proc Natl Acad Sci USA 2014; 111: 4203-4208.

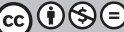

This work is licensed under a Creative Commons Attribution-NonCommercial-NoDerivs 3.0 Unported License. The images or other third party material in this article are included in the article's Creative Commons license, unless indicated otherwise in the credit line; if the material is not included under the Creative Commons license, users will need to obtain permission from the license holder to reproduce the material. To view a copy of this license, visit http://creativecommons.org/licenses/by-nc-nd/3.0/ 